\title{
Transapical aortic perfusion using a deep hypothermic procedure to prevent dissecting lung injury during re-do thoracoabdominal aortic aneurysm surgery
}

\author{
Yuya Kise, Yukio Kuniyoshi, Mizuki Ando, Hitoshi Inafuku, Takaaki Nagano and Satoshi Yamashiro
}

\begin{abstract}
Background: Avoiding various complications is a challenge during re-do thoracoabdominal aneurysm surgery. Case presentation: A 56-year-old man had undergone surgery for type I aortic dissection four times. The residual thoracoabdominal aortic aneurysm that had severe adhesions to lung parenchyma was resected. Since the proximal anastomotic site was buried in lung parenchyma, deep hypothermia was essential to avoid lung dissection and to protect the spinal cord during the proximal anastomosis. The deep hypothermia was induced with bilateral infusion of cardiopulmonary bypass by femoral artery cannulation for the lower body and by transapical cannulation for the upper body because of easy access. There was no hemorrhagic tendency after deep hypothermic bypass. The patient was discharged uneventfully.
\end{abstract}

Conclusions: For upper body perfusion, transapical aortic cannulation was a simple and effective procedure during left thoracotomy.

Keywords: Transapical aortic perfusion, Thoracoabdominal aortic aneurysm, Hypothermia, Lung injury

\section{Background}

In thoracoabdominal aortic aneurysm (TAAA) surgery with severe lung adhesions caused by repeat operations, lung dissection followed by lung injuries causes postoperative respiratory failure. To avoid lung dissection and approach the proximal anastomotic site, deep hypothermic cardiopulmonary bypass (CPB) is essential, because the procedure of approaching the proximal anastomosis is time consuming and may cause spinal cord ischemic injury under normothermic $\mathrm{CPB}$.

In cases with previous ascending aortic surgery, the approach for the $\mathrm{CPB}$ infusion site is troublesome. Transapical aortic cannulation is a novel and easy procedure for antegrade perfusion, and it could work for selective cardiac and cerebral perfusion by clamping the aorta distal to the left subclavian artery.

\footnotetext{
* Correspondence: yuya1022@med.u-ryukyu.ac.jp

Department of Thoracic and Cardiovascular Surgery, Graduate School of Medicine, University of the Ryukyus, Ryukyus, 207 Uehara, Nishihara, Okinawa 903-0215, Japan

Deep hypothermic CPB by transapical aortic cannulation might be useful in cases of a frequently operated, extended TAAA to avoid unnecessary dissection of the lung to find the proximal anastomosis and proximal aorta for cannulation.

\section{Case presentation}

The patient was a 56-year-old man who had undergone four surgical procedures for DeBakey type I dissection from 2002 to 2013: (1) graft replacement of the ascending aorta to the aortic arch (2002); (2) graft replacement of the proximal descending aorta to the Th7 level (2003); (3) Bentall operation (with a bioprosthetic valve) (2012); and (4) graft replacement of the infrarenal abdominal aorta to the bilateral external iliac arteries (2013). The remaining aorta was a TAAA from TH7 to the abdominal aorta distal to the renal artery, with a diameter of $52 \mathrm{~mm}$. In September 2014, recurrent aortic dissection occurred in the remaining TAAA (Fig. 1). 


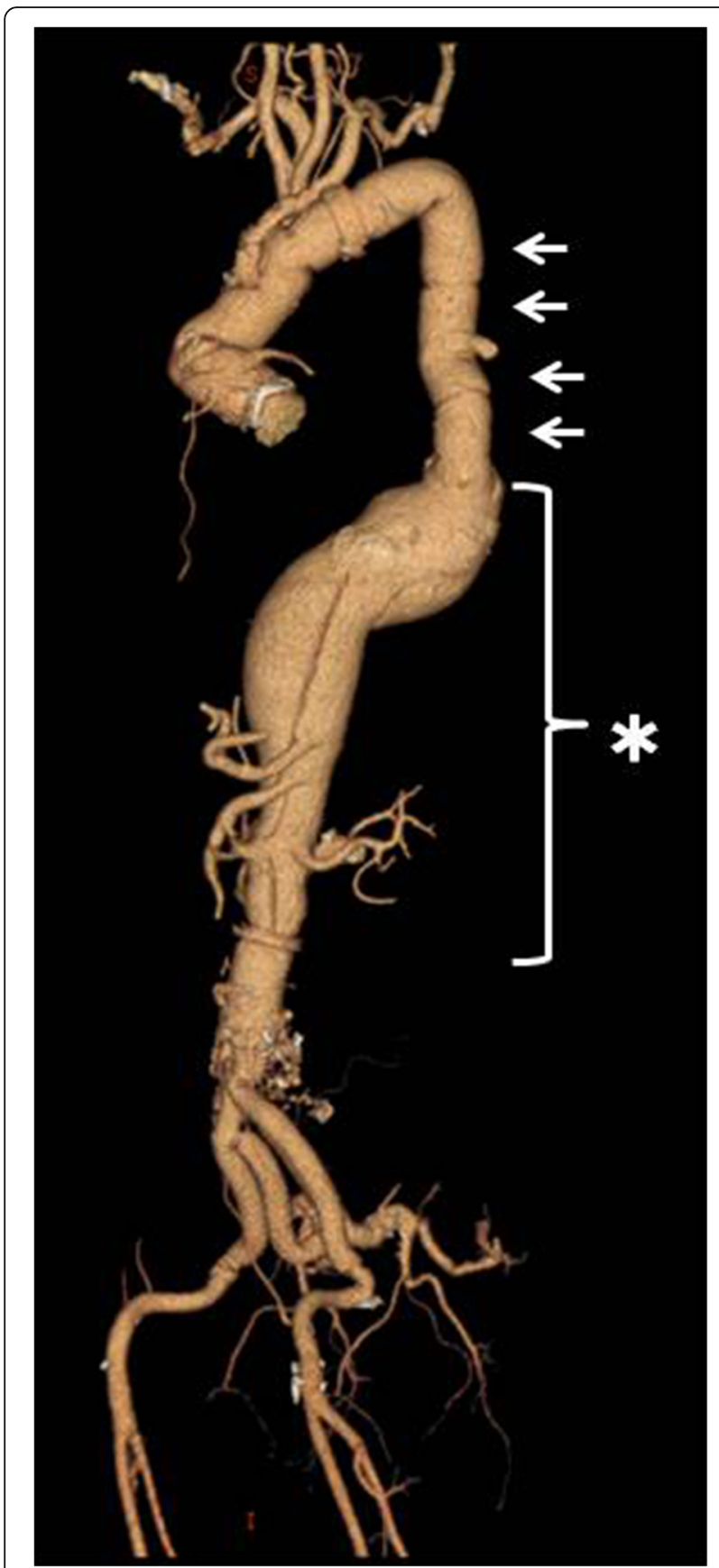

Fig. 1 Preoperative three-dimensional CT showing a chronic dissectional thoracoabdominal aortic aneurysm from the descending aorta (Th7 level) to the infrarenal aorta (asterisk). The severe adhesions between the descending prosthetic graft and the left lung are predictable (arrow)

After the symptoms of dissection subsided, the TAAA operation was performed.

\section{Operative procedure}

On a pre-operative computed tomography scan, the left side of the segmental artery at the Th11 level was identified as the Adamkiewicz artery (AKA). As for the surgical procedure, a left thoracotomy by Stoney incision was performed with the patient in the right lateral decubitus position, and the retroperitoneal space was approached. The infradiaphragmatic aortic aneurysm was exposed, but the intrathoracic aortic aneurysm could not be approached because of severe adhesions of the graft prosthesis and lung parenchyma, except for the apical portion of the left lung where there was not much adhesion to the graft prosthesis replaced in the past operation. There were also severe adhesions of the proximal thoracic aorta. As a cannulation site for upper body perfusion, the left ventricular (LV) apex was easily approached for cannulation in the ascending aorta. Heparin was administered at 300 units $/ \mathrm{kg}$, and then transapical aortic cannulation (EZ Glide 24Fr; Edwards Lifescience, Irvine, CA) was set with monitoring by transesophageal echocardiography (TEE). The right femoral artery (FEM II 16Fr; Edwards Lifescience) was cannulated for perfusion of the lower body. CPB by drainage from a long cannula from the right femoral vein to the right atrium was started, with central cooling to $16{ }^{\circ} \mathrm{C}$. After $30 \mathrm{~min}$ of sufficient core cooling, the aortic aneurysm that adhered in the thorax was excluded by clamping at just distal to the left subclavian artery and the diaphragmatic site. Cardiac and cerebral selective perfusion was established. The flow rates to the transapical cannula and the right femoral artery were regulated by pressure monitoring of the right radial artery and the left femoral artery, respectively (Fig. 2). To avoid spinal cord ischemia, motor evoked potentials (MEPs) were monitored continuously; their amplitude decreased with lowering of the body temperature, and it was zero at less than $25{ }^{\circ} \mathrm{C}$. The target of the proximal site, the distal edge of the thoracic descending prosthetic graft, was reached by incising the aneurysmal wall where it had not adhered to the lung parenchyma, and it was prepared by an encircled incision for anastomosis with a 26-mm, size 4-branch graft for TAAA (J-Graft SHIELD NEO; Japan Lifeline, Tokyo, Japan). After anastomosis, the proximal clamp forceps was released to confirm hemostasis of this anastomotic site. Sequentially, the distal clamping was moved to the distal portion of the TAAA, with reconstruction of the AKA, intercostal artery, and four major abdominal branches. Finally, the graft-graft anastomosis was done. Rewarming was started after reconstruction of the AKA and intercostal artery, and MEPs returned at a temperature greater than $25^{\circ} \mathrm{C}$. The data related to $\mathrm{CPB}$ were as follows. The time required from when the aortic cross-clamping until the proximal site anastomosis was completed was $50 \mathrm{~min}$, and the time from when aortic cross-clamping was initiated until AKA and segmental artery reconstruction was 105 min. There was no postoperative pulmonary hemorrhage. The patient was extubated on Day 4, and 


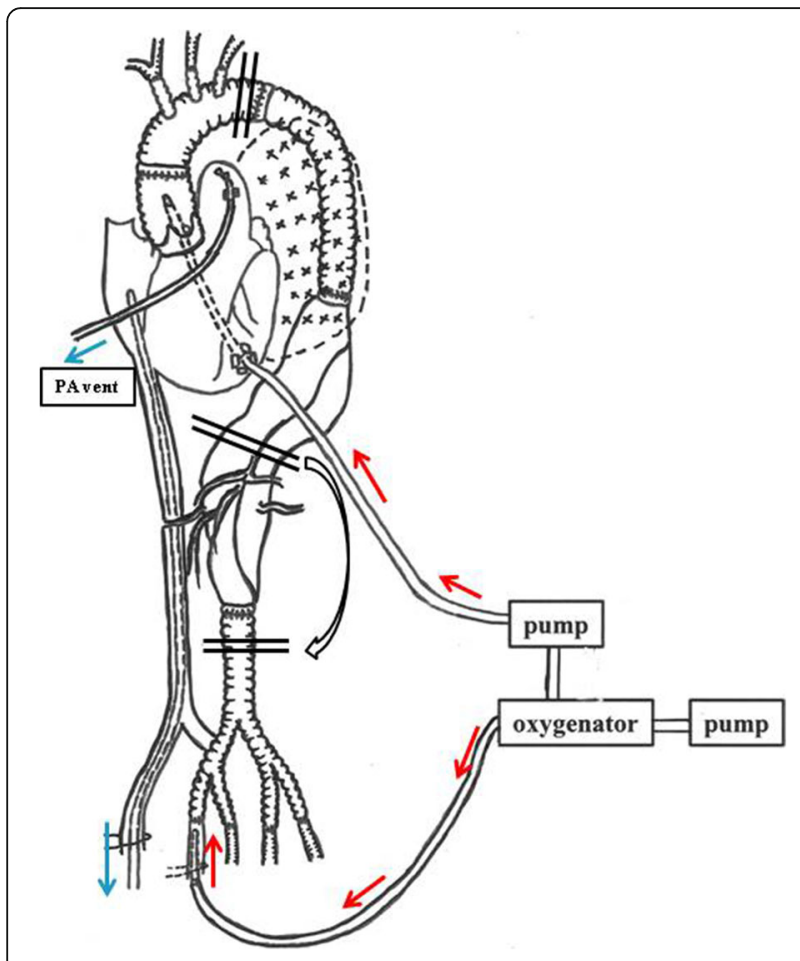

Fig. 2 Schema of perfusion technique. Transapical aortic perfusion and right femoral perfusion were done respectively. After core cooling, selective perfusion of the upper and lower body was continued under cross-clamping of the site just distal to the left subclavian artery and diaphragmatic site. After the proximal anastomosis, the distal clamp was moved to the distal portion of the TAAA

he was discharged on Day 26, able to walk independently and free of paraplegia.

\section{Discussion}

Multiple surgeries are usual for an extended aortic aneurysm, but this approach involves high operative risk, especially at re-do thoracic aortic surgery. Several postoperative morbidities, including spinal cord ischemic injury, respiratory failure, multiple organ failure, and others, have been reported. In particular, lung injury may be caused by lung dissection-induced postoperative respiratory failure, or graft infection may occur with leakage from the lung, which can be lethal. To prevent such complications, deep hypothermic technique was applied. Hypothermic CPB at TAAA surgery has been reported as a possible adjunct for organ protection by some authors [1-3]. However, there are a few reports of preventing postoperative lung complications by hypothermic CPB [3]. In this case, hypothermic CPB was used for this purpose.

However, when only deep hypothermic circulatory arrest is used, the time for proximal anastomosis is limited to approximately $30 \mathrm{~min}$, and sufficient protection of the brain and myocardium is a concern if the procedure must be prolonged. Recent reports of TAAA surgery using deep hypothermic circulatory arrest have shown relatively good results in terms of the frequency of spinal cord ischemic injury (1.3 to $5 \%$ ), but because the incidence of stroke is from 4 to $7 \%$, and the incidence of postoperative low output syndrome is from 1.2 to $14 \%$, protection of the brain and myocardium is still problematic $[1,2,4,5]$.

Continuing to use the advantages of deep hypothermic technique while also performing selective perfusion of the upper and lower body is believed to be one countermeasure to ensure cerebral and coronary perfusion and spinal cord blood supply via the collateral network from the vertebral artery, subclavian artery, internal thoracic artery, and internal iliac artery [6]. In the 1990s, the utility of selective upper and lower body blood perfusion was reported during thoracoabdominal aortic aneurysm surgery [7]. Later, a technique for changing the blood temperature and the perfusion rate selectively in the upper and lower body depending on the purpose of the protected organs was also reported [8]. The ascending aorta and thoracic descending aorta are frequently selected as the cannulation route for perfusing the upper body, but this route is not appropriate in patients with profound atherosclerotic changes, such as a shaggy and calcified aorta [9]. Shiiya et al. reported using antegrade perfusion by transapical aortic cannulation to prevent debris scattering due to retrograde perfusion from the femoral artery in a patient undergoing thoracoabdominal aortic repair by left thoracotomy [7], and Takemura et al. reported the usefulness of transapical cannulation in preventing malperfusion during a deep hypothermic procedure to repair an acute traumatic descending aortic rupture [10]. Although antegrade perfusion via the axillary artery is safe and possible [11], it is difficult to ensure the visual field during a left thoracotomy procedure.

Transapical aortic cannulation during left thoracotomy has the advantage of enabling the definitive placement of the perfusion cannula in the ascending aorta and enabling antegrade perfusion, without dislocating the heart. In this patient, too, a prosthetic graft replacement had previously been performed on the ascending to descending aorta, and direct cannulation to the graft replacement site was expected to be difficult. Transapical cannula insertion where the apex is located in front of the operating field was performed even more safely under TEE guidance, and when removing the cannula, hemostasis to the apex could be done without difficulty.

\section{Conclusion}

During re-do thoracoabdominal aortic aneurysm repair, upper body perfusion by transapical aortic cannulation might be a safe alternative technique without exposure of the proximal thoracic aorta for cannulation. 


\section{Abbreviations}

AKA: Adamkiewicz artery; CPB: Cardiopulmonary bypass; MEPs: Motor evoked potentials; TAAA: Thoracoabdominal aortic aneurysm; TEE: Transesophageal echocardiography

\section{Acknowledgements}

Not applicable.

\section{Funding}

None received.

\section{Availability of data and materials}

The data supporting the conclusion of this article are included within the article.

\section{Authors' contributions}

YK wrote the manuscript, conducted the literature review and obtained the patient's consent. All authors participated in the design of the case report and coordination, and helped to draft the manuscript. All authors read and approved of the final manuscript.

\section{Competing interests}

The authors declare that they have no competing interests.

\section{Consent for publication}

We obtained consent for publication from patient.

\section{Ethics approval and consent to participate}

Not applicable.

\section{Publisher's Note}

Springer Nature remains neutral with regard to jurisdictional claims in published maps and institutional affiliations.

Received: 18 August 2016 Accepted: 10 May 2017

Published online: 19 May 2017

\section{References}

1. Kouchoukos NT, Kulik A, Castner CF. Outcomes after thoracoabdominal aortic aneurysm repair using hypothermic circulatory arrest. J Thorac Cardiovasc Surg. 2013;145(3 Suppl):S139-41.

2. Fehrenbacher JW, Siderys H, Terry C, Kuhn J, Corvera JS. Early and late results of descending thoracic and thoracoabdominal aortic aneurysm open repair with deep hypothermia and circulatory arrest. J Thorac Cardiovasc Surg. 2010; 140(6 Suppl):S154-60.

3. Etz CD, Zoli S, Kari FA, Mueller CS, Bodian CA, Di Luozzo G, et al. Redo lateral thoracotomy for reoperative descending and thoracoabdominal aortic repair: a consecutive series of 60 patients. Ann Thorac Surg. 2009;88:758-66. discussion 67.

4. Kulik A, Castner CF, Kouchoukos NT. Outcomes after thoracoabdominal aortic aneurysm repair with hypothermic circulatory arrest. J Thorac Cardiovasc Surg. 2011;141:953-60.

5. Yoo JS, Kim JB, Joo Y, Lee WY, Jung SH, Choo SJ, et al. Deep hypothermic circulatory arrest versus non-deep hypothermic beating heart strategy in descending thoracic or thoracoabdominal aortic surgery. Eur J Cardio-Thorac Surg. 2014;46:678-84

6. Geisbusch S, Schray D, Bischoff MS, Lin HM, Griepp RB, Di Luozzo G. Imaging of vascular remodeling after simulated thoracoabdominal aneurysm repair. J Thorac Cardiovasc Surg. 2012;144:1471-8.

7. Shiiya N, Yasuda K, Murashita T, Suto Y, Kanaoka T, Matsui Y, et al. Transapical aortic cannulation for hypothermic aortic operation through a left thoracotomy: an alternative to avoid retrograde arterial perfusion. J Thorac Cardiovasc Surg. 1997:113:1113-4

8. Flores J, Shiiya N, Kunihara T, Yoshimoto K, Yasuda K. Selective perfusion of the upper and lower body under different levels of hypothermia in a patient with coronary artery disease and dissecting thoracoabdominal aortic aneurysm. Ann Thorac Cardiovasc Surg. 2004;10(3):205-8.

9. Fukuda I, Daitoku K, Minakawa M, Fukuda W. Shaggy and calcified aorta: surgical implications. Gen Thorac Cardiovasc Surg. 2013;61:301-13.

10. Takemura T, Shimamura Y, Sakaguchi M, Tsuda Y, Iwasa S. Transapical aortic cannulation using a deep hypothermic procedure through a left thoracotomy for acute traumatic aortic rupture. Jpn J Thorac Cardiovasc Surg. 2003;51:619-21.

11. Kawaharada N, Ito T, Naraoka S, Hagiwara T, Koyanagi T, Kurimoto Y, et al. Right axillary arterial perfusion for descending thoracic or thoracoabdominal aortic aneurysm repair with open proximal anastomosis through left thoracotomy. Gen Thorac Cardiovasc Surgery. 2014;62:547-52.

\section{Submit your next manuscript to BioMed Central and we will help you at every step:}

- We accept pre-submission inquiries

- Our selector tool helps you to find the most relevant journal

- We provide round the clock customer support

- Convenient online submission

- Thorough peer review

- Inclusion in PubMed and all major indexing services

- Maximum visibility for your research

Submit your manuscript at www.biomedcentral.com/submit 